Lucrările Seminarului Geografic Dimitrie Cantemir

Vol. 45, October 2017, pp. 159-170

http://dx.doi.org/10.15551//sgdc.v45i0.12

\title{
The implications of the globalization process on the Spanish football championship 2016-2017
}

\section{Cristian-Ionuț Manolache ${ }^{1}$}

${ }^{1}$ Alexandru Ioan Cuza University of Iasi, Romania.

To cite this article: Manolache, C.-I. (2017). The implications of the globalization process on the Spanish football championship 2016-2017. Lucrările Seminarului Geografic Dimitrie Cantemir, Vol. 45, pp. 159-170. DOI: $10.15551 /$ lsgdc.v45i0.12

To link to this article: http://dx.doi.org/10.15551/lsgdc.v45i0.12 


\title{
THE IMPLICATIONS OF THE GLOBALIZATION PROCESS ON THE SPANISH FOOTBALL CHAMPIONSHIP 2016-2017
}

\author{
Cristian-Ionuţ Manolache ${ }^{1}$
}

\begin{abstract}
The main purpose of the research is to demonstrate that the implications of globalization process on the first league of the Spanish football championship have led to a change in the composition of teams in favor of sport performances. Today's sports competition from La Liga is not only for the elite of the Spanish football, but also for a conglomerate of athletes from all over the world.
\end{abstract}

Keywords: globalization, football, transfers, nationality, performance.

\section{Introduction}

J. Maguire (2011) says that national identities are subject to a process of dislocation which is clearly correlated with globalization processes. In some places, local cultures or identities are strengthened by showing resistance and an increasing variety between them. In other places the contrasts between cultures decrease by decreasing the differences.

Football is one of the most dynamic components of globalization from a sociological point of view. The strongest brands of football are usually associated with long term performances both at national and international levels. Recruiting elite players from all over the world contributes to capitalizing the club's brand. (Richard, G., Roland, R. 2004)

The migration of athletes, coaches or sports specialists between nations and continents is a feature of twentieth century sport. The migration of elite sports talent has become a decisive element in the sport structures of society. (Maguire, J. 2000)

As my predecessors from domain of Geography of Sports, we can remark the implications of the globalization process in football. The most powerful clubs in the Spanish championship have in their team football players from all over the world to achieve their goals.

Sport performance is no longer achieved only through local footballers but with the help of the world's elite. This phenomenon involved financial implications in football which propels teams to performance, but in the same time changes the perception of national or local identity.

This analysis wants to demonstrate that the first Spanish football league is affected by the processes of globalization in all its social, economic or image components. We will also be able to see if is an interrelated feedback between the social, economic and image (performances) elements.

\footnotetext{
1 "Alexandru Ioan Cuza" University of Iasi, Doctoral School of Geosciences, Romania, Vaslui, manolachecristianionut@gmail.com
} 


\section{Methodology}

In order to analyze the performance of the Spanish Premier League soccer clubs in the competitive season 2016-2017, we used seven variables, resulting in five distinct classes. Of these, the percentage of victories from total games played, average of goals scored on game, average of points achieved on game and the UEFA Clubs Coefficient, rank in descending order the performance of the athletes.

On the other hand, variables like the percentage of defeats from total games played and average of goals received on game, rank in ascending order the competitiveness of the football players. Clubs that do not excel in the last two variables are sports performance symbols. The first four variables listed are in opposition to the last two. In principle, the teams at the top of the ranking excel in the first category of variables, and the last ones of the ranking excel in the second category of variables.

The seventh variable, the percentage of draws from total games played, brings a balance in the final hierarchy, favors the teams who are in middle and background of the ranking and disadvantage those who are trying to win the competition.

The "social" analysis of the football clubs from Primera División gives an overview on the behavior of supporters, in terms of supporting the favorite team to the games on their own field and regarding the globalization of the squad of players, resulting four distinct classes.

Supporting the favorite team in the confrontations on their own field will be analyzed according to three variables: average of viewers at home games, occupancy rate of stadium and percentage of viewers per game from the total population of the club's home town for year 2016, estimated by „City Population”. Average of viewers at home games was calculated by dividing the total number of spectators present at games played on their own field to nineteen. And the occupancy rate of the stadium was calculated by dividing the total number of spectators multiplied by one hundred to the total capacity of the stadium.

$$
\mathrm{ORS}=\mathrm{NV} * 100 / \mathrm{TCS}
$$

ORS = occupancy rate of the stadium;

$\mathrm{NV}=$ total number of viewers at home games;

TCS $=$ total stadium capacity at home games;

$$
\mathrm{TCS}=\mathrm{CS} * 19
$$

$\mathrm{CS}$ = capacity of the stadium;

$19=$ total number of games played at home.

The percentage of viewers per game from the total population was calculated by dividing the average of spectators at home games multiplied by one hundred to the population of the clubs home town.

The process of globalization of the squad of players is analyzed in the present study by means of two variables: a) percentage of Spanish players compared to b) percentage of foreign players.

By "economic analysis" we understand the financial implications that have contributed to the realization of the transfers and the achievement of the performances. The variables used to describe the economic capacity of clubs are: the percentage of expenditure made with 
transfers from the GDP of 2014 for the NUTS3 region of the teams, the spending average with transfers for the past five seasons, the revenue average from transfers for past five seasons and the average of player market value for season 2016-2017.

The percentage of expenditure on transfers from GDP was calculated by dividing the spending average with transfers for the past five seasons multiplied by one hundred to the GDP of 2014 for the NUTS3 region of the clubs. We used the year 2014, because it is the latest data provided by Eurostat to the public.

We decided to use the average of spending / revenue with transfers for the last five seasons, because it provides a relevant understanding into a clubs investment and income, directly affecting the team's performance and structure. If we had only used the income and expenditure of the analyzed season, the resulting hierarchy would not have been relevant, because clubs are not active on the transfer market every season, they can choose for continuity at squad level. Just looking on a longer period, we can see the financial strength of a club and its typology in the transfer market. We think the five year period is relevant to this study, because the transfer market is in a continuous acceleration, team players are constantly changing and most of the time the transactions older than five years are no longer relevant to the present.

The average of player market value was calculated by dividing the total market value of the squad to the number of players. We cannot say that amounts for which players are being evaluated by Transfermarkt are accurately established, but it gives us an overview of the differences between football clubs.

For the Spanish football championship typology we chose the most significant variables, to give an overview on the implications of the phenomenon of globalization in economic and social structures or sports performance.

As a result, we selected as indicators: the average of points achieved on game to illustrate sports performance; the average of viewers at home games and percentage of Spanish players compared to the percentage of foreign players to analyze social implications. Economic valences are represented by the average spending on transfers for the past five seasons and the average of player market value.

\section{Research results}

\subsection{The analysis of clubs "performances" from La Liga 2016-17}

At the top of the hierarchy of victory percentage in all matches played is Real Madrid, with $76.31 \%$, Barcelona, with $73.68 \%$ and Atlético Madrid, with $60.52 \%$. The clubs representative for the percentage of draws from all games played are: Alavés (34.21\%), Deportivo La Coruña, (21.05\%) and Espanyol (39.47\%).

The biggest value for the percentage of defeats from total games played is specific to teams like: Granada (68.42\%), Osasuna (63.15\%) and Sporting Gijón (55.26\%). The highest average of goals scored on game is representative to Barcelona (3.05), Real Madrid (2.78) and Atlético Madrid (1.84). And the biggest average of goals received on game is specific for Osasuna (2.47), Granada (2.15) and Las Palmas (1.94).

In the final hierarchy of the clubs from La Liga is Real Madrid with an average of points achieved on game of 2.44, Barcelona with an average of 2.36 points and Atlético Madrid with an average of 2.05 points. At the European level, Real Madrid achieved 37028 points in the 
UEFA Clubs Coefficient, being the winner of the Champions League; Atlético Madrid achieved 33028 points reaching the semifinals and Barcelona achieved 27028 points playing in the quarterfinals.

Interpreting Figure 1 we can notice that Real Madrid and Barcelona have a high yield for all variables, with values above the average for the percentage of victories, average of goals scored, average of points achieved on game and the UEFA Clubs Coefficient. They having below average values for average of draws and defeats and for average of goals received.

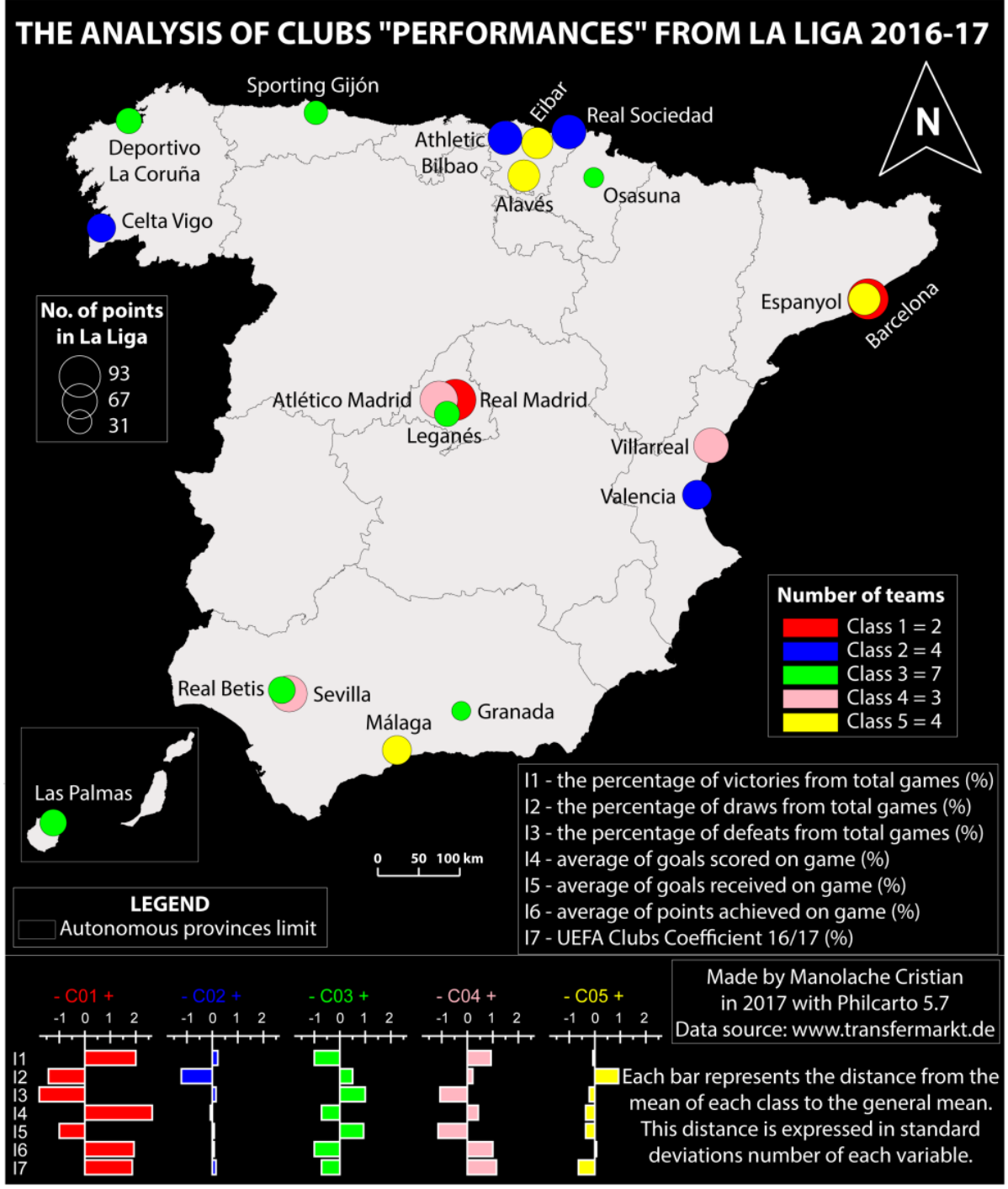

Figure 1: The analysis of clubs "performances" from La Liga 2016-17

The second class is specific to Real Sociedad, Athletic Bilbao, Celta Vigo and Valencia. They stand out through a lower average of draws from total games in comparison to the teams in the first class. This phenomenon indicates that clubs have tried to get all the points at almost every game. The first two teams have a victory percentage of $50 \%$ and the last two have a 
percentage of $34.21 \%$. Specific to clubs from second class is that in recent years they have participated in European competitions.

The third class is specific to the last seven clubs in the final hierarchy of the ranking: Las Palmas, Real Betis, Deportivo La Coruña, Leganés, Sporting Gijón, Osasuna and Granada. Teams from this class are the opposite of the first category, having high values for the variables that Real Madrid and Barcelona have avoided, like average of draws or defeats from total games and average of goals received on game.

Atlético Madrid, Sevilla and Villarreal are exponents of the fourth class, ranking on places 3-4 and 5 in La Liga. They showed a similarly statistically behavior as teams from the first class, Real Madrid and Barcelona, but they have the values of variables closer to the average. And the percentage of draws from total games played is higher, disadvantaging them if the final hierarchy.

The last class is specific to clubs from the top of the middle of ranking, Espanyol, Alavés, Eibar and Málaga. Characteristic for these is the over average value of draws and the closer value to the average of points achieved on game; specific variables for the middle teams from the final hierarchy.

From a spatial point of view, we cannot find a group of individuals specific to a particular class in a well-defined geographic space, the distribution of sports performances being random.

\subsection{The "social" analysis of clubs from La Liga 2016-17}

From data analysis, clubs that excel at the average of viewers at home games are Barcelona, with 77034 viewers, Real Madrid (68028), Atlético Madrid (44671) and Athletic Bilbao (41120). In opposition, Eibar has an average of 5311 viewers at home matches, Leganés (9317), Osasuna (14812) and Granada (14994).

The stadium occupancy rate in the La Liga 2016-17 season can be divided into four major categories:

- $\quad$ over $80 \%$, of which belong: Leganés, with $85.30 \%$ and Atlético Madrid, with $81,35 \%$;

- 79.99-70\% - Real Madrid, Osasuna, Sporting Gijón, Barcelona, Athletic Bilbao, Sevilla, Alavés, Eibar and Málaga;

- 69.99-60\% - Villarreal, Deportivo La Coruña, Granada, Real Sociedad, Real Betis, Valencia and Las Palmas;

- less than 60\% - Celta Vigo (56.76\%) and Espanyol (49.56\%).

As regards the percentage of viewers per match from the total population, four categories can be delimited:

- $\quad$ over 10\% - Villarreal (34.55\%), Eibar (19.39\%), Athletic Bilbao (11.91\%) and Real Sociedad (11.50\%);

- 9.99-5\% - Deportivo La Coruña, Sporting Gijón, Osasuna, Granada, Alavés, Celta Vigo and Las Palmas;

- 4.99-4\% - Leganés, Barcelona, Sevilla, Real Betis and Valencia; 
- less than 4\% - Málaga (3.89\%), Real Madrid (2.14\%), Atlético Madrid (1.41\%) and Espanyol (1.24\%).

In the localities where two teams are present in the first division, we can see between them a distribution of percentage of spectators from the total population. In the case of Barcelona City, the team with the same name has a higher percentage of spectators compared to Espanyol. And in Madrid City, the Real outperforms Atlético from the same point of view. It results that in both cases, Barcelona and Real Madrid, can be classified as football clubs exponents of the city. On the other hand, Sevilla and Real Betis have an almost identical percentage of viewers, splitting them equally.

From the point of view of national identity, $75 \%$ of teams from the first league have a percentage of Spanish players bigger than 50\%, remarking Athletic Bilbao, with a percentage of $97.14 \%$, Real Sociedad, with $85.29 \%$ and Eibar $(84.21 \%)$. On the other hand there are Granada, with a percentage of $69.76 \%$ of foreign players, Atlético Madrid (65.95\%), Sevilla (60\%) Málaga (52.77\%) and Real Madrid (51.51\%).

Interpreting Figure 2 we can notice that in the first class are football clubs like Real Madrid, Barcelona, Atlético Madrid, Sevilla, Málaga and Granada. They have values above the average for the following variables: average of viewers at home games, occupancy rate of stadium or percentage of foreign players. They have values below the average for the percentage of viewers per match from total population and percentage of Spanish players. On average, we can say that supporters from first class teams are attracted to the spectacle present by the favorite teams. And their squads are cosmopolitan with players around the world.

The second class is specific to Athletic Bilbao, Alavés, Eibar, Leganés, Sporting Gijón and Osasuna. They are above average as regards the occupancy rate of the stadium, the percentage of spectators per game from total population and the percentage of Spanish players. The phenomenon indicates that, although they do not have a very large number of viewers, compared to Real Madrid or Barcelona, the local population supports the city team by raising the stadiums occupancy rate. Also, we can say that teams from the second class have the greatest national resistance to the globalization process that has conquered the world of football as well.

The third class is specific to Real Sociedad, Espanyol, Valencia, Celta Vigo, Las Palmas, Real Betis and Deportivo La Coruña. Teams from this category have negative values for most variables, except for the percentage of Spanish players. The worst part comes from the fact that the stadium occupancy rate is the lowest from the championship, which means that teams' performance must be improved, so that they can attract a significant amount of viewers.

The fourth class is made up of a single football club, Villarreal, which differentiates itself from other competitors through the high percentage of viewers per game from total population. Because of the results and spectacular game, Villarreal manages to attract the attention from a high percentage of local and regional audience, taking into account that population is not much over 50000 inhabitants.

From a spatial point of view, we can see a group of clubs specific to class number two (except Leganés) in northern Spain, the conglomeration being better established in the Basque Country. Specific to these teams is the high percentage of Spanish players, the basque population being a symbol of the local resistance against the global changes. 
On the other hand, Madrid area, southern Spain and Barcelona FC are basically vectors of globalization within the Spanish championship, having a high percentage of foreign players, which contribute to achieving European performance (Real Madrid, Barcelona, Atlético Madrid and Sevilla).

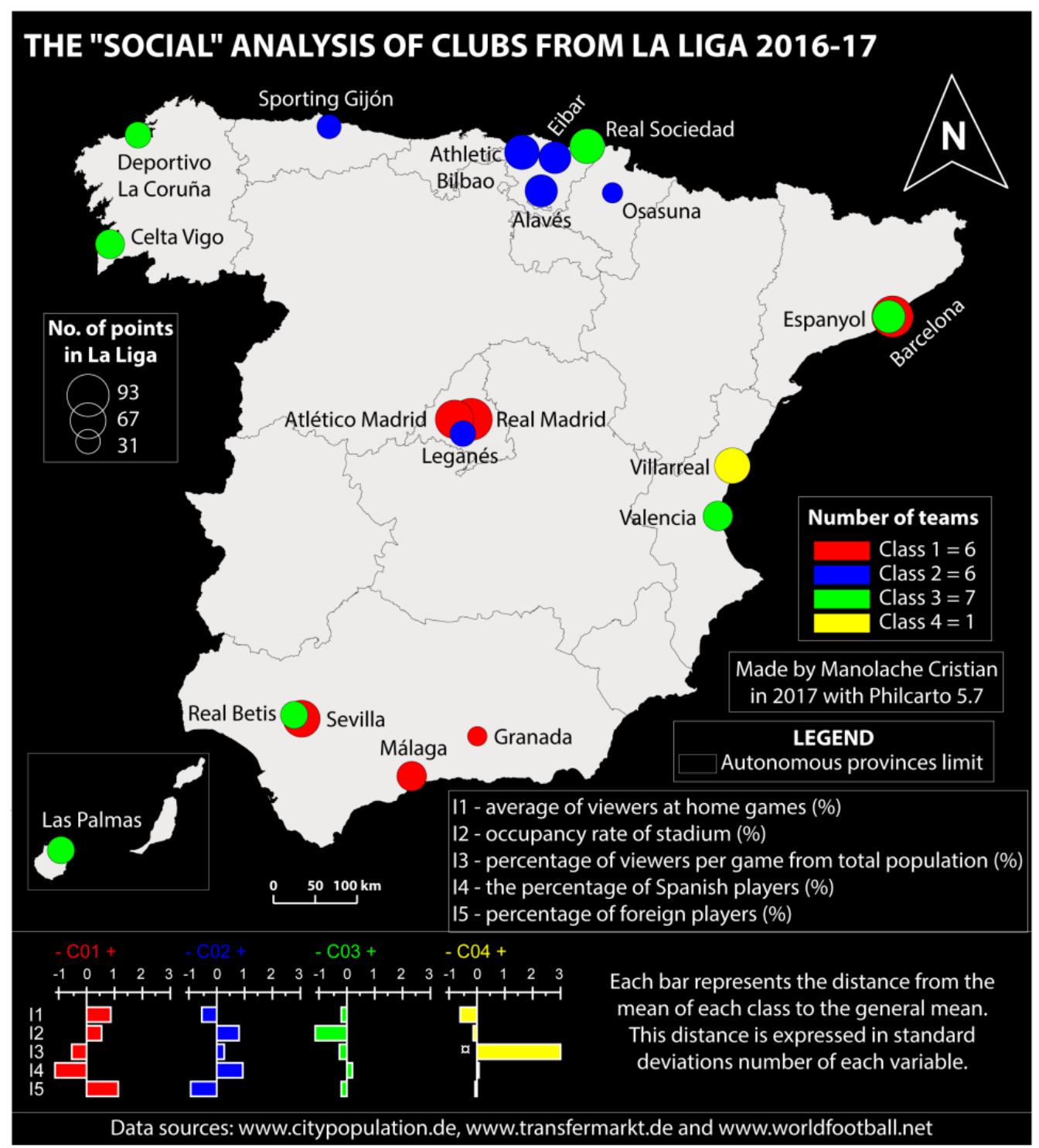

Figure 2: The "social" analysis of clubs from La Liga 2016-17

\subsection{The "economic" analysis of clubs from La Liga 2016-17}

Analyzing the data, we can classify the percentage of expenditure with transfers from GDP 2014 in four categories: 
1) over $100 \%$, of which belong: Villarreal (222.14\%), Las Palmas (111.42\%), Sevilla $(107.13 \%)$ and Valencia (106.55\%);

2) $99.99-30 \%$ - Real Sociedad, Barcelona, Granada, Real Madrid, Celta Vigo and Atlético Madrid;

3) 29.99-10\% - Real Betis, Málaga, Athletic Bilbao, Deportivo La Coruña, Eibar and Alavés;

4) less than 10\% - Osasuna (6.61\%), Espanyol (2.98\%), Sporting Gijón (1.94\%) and Leganés (0.24\%).

At the top of the spending average with transfers for the past five seasons there are Barcelona, with $€ 94.93 \mathrm{~m}$, Real Madrid, with $€ 91.1 \mathrm{~m}$, Atlético Madrid $(€ 75.31 \mathrm{~m})$, Valencia $(€ 55.74 \mathrm{~m})$ and Sevilla $(€ 37.36 \mathrm{~m})$, and in opposition it is: Las Palmas $(€ 1.56 \mathrm{~m})$, Alavés $(€ 1.20 \mathrm{~m})$, Osasuna $(€ 1.18 \mathrm{~m})$, Leganés $(€ 470 \mathrm{k})$ and Sporting Gijón (€400k).

As regards the revenue average from transfers for the past five seasons we can remark Atlético Madrid, with $€ 75.95 \mathrm{~m}$, Sevilla, with $€ 62.66 \mathrm{~m}$, Real Madrid, with $€ 62.57 \mathrm{~m}$ and Valencia $(€ 59.11 \mathrm{~m})$. In opposition, at the basis of the hierarchy are clubs like Las Palmas $(€ 1.21 \mathrm{~m})$, Eibar $(€ 1.12 \mathrm{~m})$, Alavés (€200k) and Leganés (€60k).

The average of player market value clearly separates Real Madrid $(€ 22.51 \mathrm{~m})$ and Barcelona $(€ 21.27 \mathrm{~m})$ from the other teams, which have an average of less than $€ 10$ million. Resulting that, in case of the first two clubs the squad is composed from a higher number of elite footballers who contributed to team evolution and to achieve the performance.

Interpreting Figure 3 we can notice that in the first class are football clubs Real Madrid and Barcelona which have values above average for all the variables analyzed. The percentage of expenditure with transfers from GDP is very close to the championship average, because those two clubs having their geographical origin in NUTS3 regions with a strong economic activity. Also, clubs are characterized by a spending average with transfers for past five seasons bigger than income and the average of player market value is higher than that of other counter candidates.

The second class is specific to Athletic Bilbao, Espanyol, Alavés, Eibar, Real Betis, Deportivo La Coruña, Leganés, Sporting Gijón and Osasuna, which presents values lower than average for all variables analyzed.

The third class is specific to Atlético Madrid, Sevilla and Valencia. Teams in this category have positive values for all variables. It differs from the clubs in the first class through a bigger percentage of expenditure with transfers from GDP, revenue from transfers higher than expenses and an average of player market value closer to the championship average.

And this time, Villarreal is different from the rest of the championship forming a class with one individual. The main way of differentiation is accomplished by the percentage of expenditure with transfers from GDP which exceeds $200 \%$. The club has higher revenue than spending and an average of player market value lower than the average of the championship.

The last class is specific to Real Sociedad, Málaga, Celta Vigo, Las Palmas and Granada. They present values below the championship average for most of the variables, excepting the percentage of expenditure with transfers from GDP.

From a spatial point of view, we can see a division of clubs into three regions. The northern part has little involvement on the transfer market and has a lower average of player market value. The same is valuable to the southeastern Iberian peninsula and the Canary Islands. In opposition, the central part of Spain, with extension in the northeast (Barcelona) and southwest (Sevilla), presents high values for all the analyzed financial variables. 


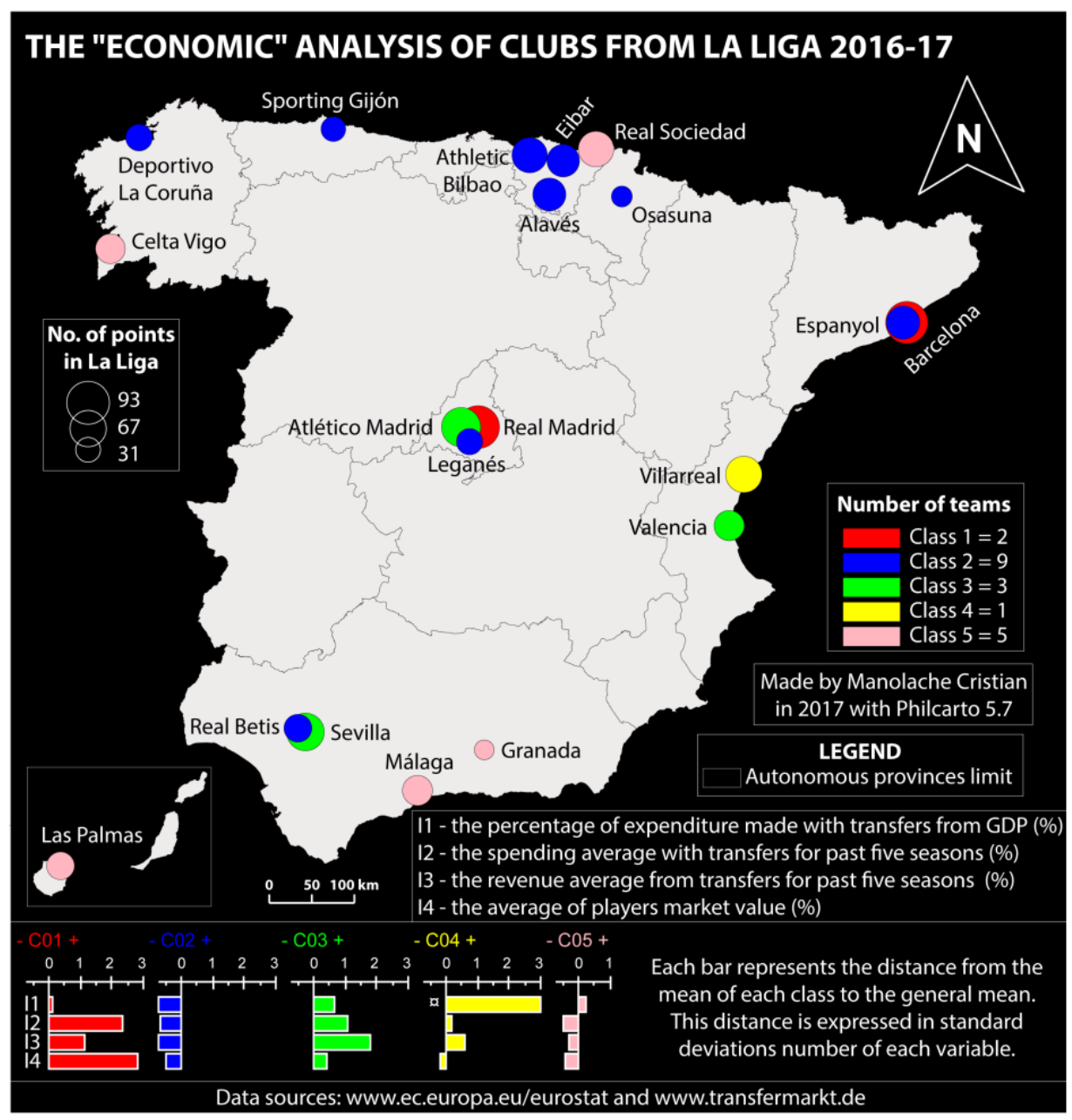

Figure 3: The "economic" analysis of clubs from La Liga 2016-17

\subsection{The typology of clubs from La Liga 2016-2017}

In the first class are included football clubs Real Madrid and Barcelona, which have a high yield for variables of sport performances, average of viewers, investment and the market value of the players. And the percentage of domestic players is lower than that of foreigners. From the point of view of globalization we can say that Real Madrid and Barcelona have in their teams exponents of the global elite, which perform locally and worldwide.

The second class is specific to Real Sociedad, Athletic Bilbao and Eibar, which stand out htough a high percentage of Spanish players and an average of the points achieved on game higher than the championship average. From the previous analysis, we can say that the Basque Country teams show a form of resistance against globalization, trying to promote local and national talent to the detriment of top performances. 
The third class is specific to Villarreal, Espanyol, Alavés, Málaga, Valencia, Celta Vigo, Real Betis, Deportivo La Coruña and Granada. Teams from this category generally have lower values than the average for all variables and a higher percentage of foreign players.

Atlético Madrid and Sevilla are the fourth class exponents having similar valances like the teams in the first class, Real Madrid and Barcelona. They are differentiated by the fact that the first four indicators have values closer to the average (sports performance being lower, as well as economic implications).

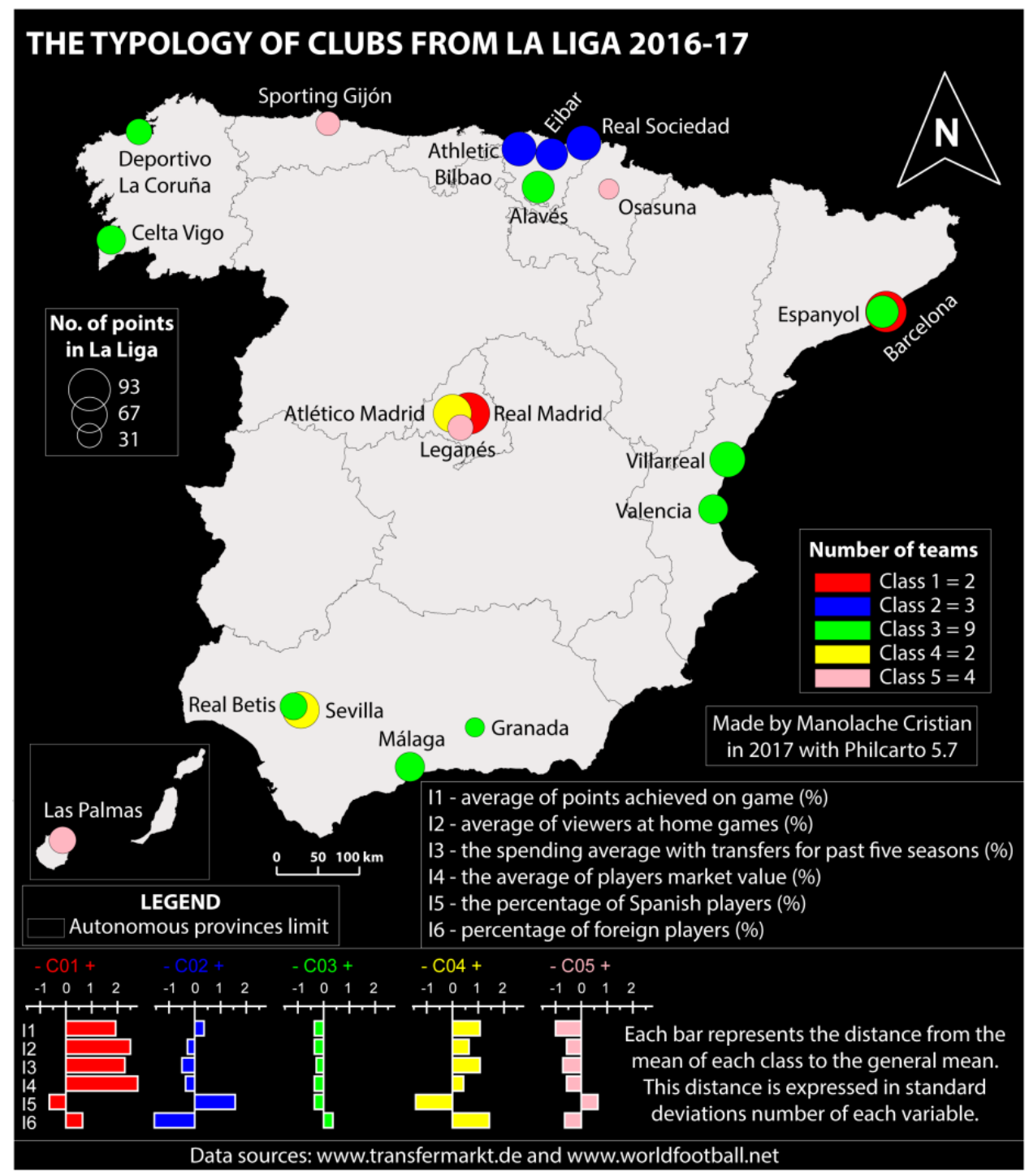

Figure 4: The typology of clubs from La Liga 2016-17

Atlético Madrid and Sevilla have a high degree of globalization within the squad, with a high percentage of foreign players, even compared to Real Madrid and Barcelona which also integrate the Spanish football elite. 
The last class is specific to Las Palmas, Leganés, Sporting Gijón and Osasuna. Their features are similar to those of the teams in the third class, but sports performance is lower on average. And the teams in class five have a higher percentage of Spanish players compared to foreigners.

\section{Conclusions}

Starting from the idea that some local cultures or identities are strongly against the processes of globalization, we can conclude that teams representing the first league of the Spanish football championship from the Basque Country oppose the phenomenon with a high percentage of Spanish players in their teams.

On the other hand, decreasing differences between cultures and football identities through a mix of players from around the world is specific to the elite of Spanish football, Real Madrid, Barcelona, Atlético Madrid and Sevilla, which achieve their sports performances both at national and European level through infusion of capital into the transfer market. Their teams are composed of exponents of the world elite.

The typological analysis of Spanish football championship proves that teams which have the highest average of points achieved on game also have the highest percentage of foreign players.

The extreme example of feedback between social, economic and sports performance components is Villarreal. To be able to compete against the most important Spanish football clubs, it invests in the transfer market, on average, the double GDP of the NUTS3 region it belongs to. And as a result, it manages to attract an impressive percentage of supporters.

\section{References}

1. Maguire J., 2000. Sport and globalisation, Entry For: Sport and Development Web-Based Platform, Swiss Academy for Development, Switzerland.

2. Maguire, J., 2011. Globalization, sport and national identities, Sport in Society: Cultures, Commerce, Media, Politics, vol. 14, no. 7/8, pp. 978-993, Routledge: Taylor \& Francis Group.

3. Richard, G., Roland, R., 2004. The globalization of football: a study in the glocalization of the 'serious life', The British Journal of Sociology, vol. 55, no. 4.

4. City Population (www.citypopulation.de) - consulted between 10 and 14 August 2017.

5. Eurostat (www.ec.europa.eu/eurostat) - consulted between 10 and 14 August 2017.

6. Transfermarkt (www.transfermarkt.de) - consulted between 10 and 14 August 2017.

7. World Football (www.worldfootball.net) - consulted between 10 and 14 August 2017. 
